\title{
Review
}

Clinical Care/Education

Diabetes Metab J 2019;43:398-406

https://doi.org/10.4093/dmj.2019.0137

pISSN 2233-6079 · eISSN 2233-6087

DIABET\&S \& METABOLISM JOURNAL

\section{Clinical Practice Guidelines for Type 2 Diabetes Mellitus in Korea}

\author{
Mee Kyoung Kim ${ }^{1}$, Seung-Hyun $\mathrm{Ko}^{2}$, Bo-Yeon $\mathrm{Kim}^{3}$, Eun Seok Kang ${ }^{4}$, Junghyun Noh' ${ }^{5}$, Soo-Kyung Kim ${ }^{6}$, Seok-O Park ${ }^{7}$, \\ Kyu Yeon Hur ${ }^{8}$, Suk Chon ${ }^{9}$, Min Kyong Moon ${ }^{10}$, Nan-Hee Kim ${ }^{11}$, Sang Yong Kim ${ }^{12}$, Sang Youl Rhee ${ }^{9}$, Kang-Woo Lee ${ }^{13}$, \\ Jae Hyeon $\mathrm{Kim}^{8}$, Eun-Jung Rhee ${ }^{14}$, SungWan Chun ${ }^{15}$, Sung Hoon $\mathrm{Yu}^{16}$, Dae Jung Kim ${ }^{17}$, Hyuk-Sang Kwon ${ }^{1}$, Kyong Soo Park ${ }^{18,19}$, \\ Committee of Clinical Practice Guidelines, Korean Diabetes Association \\ ${ }^{1}$ Division of Endocrinology and Metabolism, Department of Internal Medicine, Yeouido St. Mary's Hospital, College of Medicine, The Catholic University of \\ Korea, Seoul, \\ ${ }^{2}$ Division of Endocrinology and Metabolism, Department of Internal Medicine, St. Vincent's Hospital, College of Medicine, The Catholic University of Korea, \\ Suwon, \\ ${ }^{3}$ Division of Endocrinology and Metabolism, Department of Internal Medicine, Soonchunhyang University Bucheon Hospital, Soonchunhyang University \\ College of Medicine, Bucheon, \\ ${ }^{4}$ Department of Internal Medicine, Yonsei University College of Medicine, Seoul, \\ ${ }^{5}$ Division of Endocrinology and Metabolism, Department of Internal Medicine, Inje University Ilsan Paik Hospital, Inje University College of Medicine, Goyang, \\ ${ }^{6}$ Division of Endocrinology and Metabolism, Department of Internal Medicine, CHA Bundang Medical Center, CHA University, Seongnam, \\ ${ }^{7}$ Gwangmyeong Sungae Hospital, Gwangmyeong, \\ ${ }^{8}$ Division of Endocrinology and Metabolism, Department of Medicine, Samsung Medical Center, Sungkyunkwan University School of Medicine, Seoul, \\ ${ }^{9}$ Department of Endocrinology and Metabolism, Kyung Hee University School of Medicine, Seoul, \\ ${ }^{10}$ Department of Internal Medicine, Seoul Metropolitan Government Seoul National University Boramae Medical Center, Seoul National University College of \\ Medicine, Seoul, \\ ${ }^{11}$ Department of Internal Medicine, Korea University College of Medicine, Ansan, \\ ${ }^{12}$ Division of Endocrinology and Metabolism, Department of Internal Medicine, Chosun University College of Medicine, Gwangju, \\ ${ }^{13}$ Sejong St. Mary's Diabetes and Endocrine Clinic, Sejong, \\ ${ }^{14}$ Division of Endocrinology and Metabolism, Department of Internal Medicine, Kangbuk Samsung Hospital, Sungkyunkwan University School of Medicine, \\ Seoul, \\ ${ }^{15}$ Department of Internal Medicine, Soonchunhyang University Cheonan Hospital, Soonchunhyang University College of Medicine, Cheonan, \\ ${ }^{16}$ Department of Endocrinology and Metabolism, Hanyang University Guri Hospital, Hanyang University College of Medicine, Guri, \\ ${ }^{17}$ Department of Endocrinology and Metabolism, Ajou University School of Medicine, Suwon, \\ ${ }^{18}$ Department of Molecular Medicine and Biopharmaceutical Sciences, Graduate School of Convergence Science and Technology, Seoul National University, Seoul, \\ ${ }^{19}$ Department of Internal Medicine, Seoul National University College of Medicine, Seoul, Korea
}

The Committee of Clinical Practice Guidelines of the Korean Diabetes Association revised and updated the 6th Clinical Practice Guidelines in 2019. Targets of glycemic, blood pressure, and lipid control in type 2 diabetes mellitus (T2DM) were updated. The obese and overweight population is increasing steadily in Korea, and half of the Koreans with diabetes are obese. Evidence-based recommendations for weight-loss therapy for obesity management as treatment for hyperglycemia in T2DM were provided. In addition, evidence from large clinical studies assessing cardiovascular outcomes following the use of sodium-glucose cotransporter-2 inhibitors and glucagon-like peptide 1 receptor agonists in patients with T2DM were incorporated into the recommendations.

Keywords: Diabetes mellitus, type 2; Diagnosis; Practice guideline; Therapeutics

\section{INTRODUCTION}

The prevalence of type 2 diabetes mellitus (T2DM) in Korea is estimated to be $14.4 \%$ (in those over 30 years of age), according to a report by the Korean National Health and Nutrition Examination Survey 2011 to 2016 [1]. The prevalence of diabetes
Corresponding author: Hyuk-Sang Kwon (iD https://orcid.org/0000-0003-4026-4572 Division of Endocrinology and Metabolism, Department of Internal Medicine, Yeouido St. Mary's Hospital, College of Medicine, The Catholic University of Korea, 10 63-ro, Yeongdeungpo-gu, Seoul 07345, Korea E-mail: drkwon@catholic.ac.kr
This is an Open Access article distributed under the terms of the Creative Commons Attribution Non-Commercial License (http://creativecommons.org/licenses/by-nc/4.0/) which permits unrestricted non-commercial use, distribution, and reproduction in any medium, provided the original work is properly cited. 
mellitus (DM) increased in both men and women as age increased and the prevalence of DM exceeded $10 \%$ for men in their 40 s and $10 \%$ for women in their 50s. The obese and overweight population is also increasing steadily in Korea. Half of the people with DM are obese; class II obesity (body mass index [BMI] 30.0 to 34.9 ) is $8.4 \%$ and class III obesity (BMI $\geq 35.0$ ) is $1.8 \%$ in people with DM [1]. Thus the early detection and prevention of T2DM are major health concerns for Koreans and the government. The diagnosis and appropriate treatment for T2DM are very important issues in establishing and implementing high-priority health policies in Korea.

\section{DIAGNOSIS OF TYPE 2 DIABETES MELLITUS}

The diagnostic criteria for T2DM are based on the plasma glucose, either the fasting plasma glucose (FPG) or the 2-hour plasma glucose during a 75-g oral glucose tolerance test (OGTT), or glycated hemoglobin (HbAlc) value (Table 1). The HbAlc test should be performed using a method that is certified by the National Glycohemoglobin Standardization Program (NGSP) and standardized or traceable to the Diabetes Control and Complications Trial (DCCT) reference assay [2]. In Korea, HbAlc standardization has been widely performed since 2007 [3], and since 2011, HbA1c has been included as a diagnostic criterion for the Korean Diabetes Association clinical practice guidelines [3]. Unless there is a clear diagnosis (classic symptoms of DM with a random plasma glucose $200 \mathrm{mg} / \mathrm{dL}$ ), diagnosis requires two abnormal test results from the same sample or in two separate samples. If two different tests (HbAlc and FPG) are both above the diagnostic criteria when analyzed from the same sample or same day, this confirms the diagnosis of DM. According to the study of 4,481 Korean people with HbA1c and FPG, but with no diabetic medications in the Korean National and Nutritional
Examination Survey, the HbA1c levels corresponding to the FPG of 100 and $126 \mathrm{mg} / \mathrm{dL}$ were $5.75 \%$ and $6.42 \%$, respectively [4]. Therefore, the suitable cutoff value of $\mathrm{HbAlc}$ for the diagnosis of DM in the Korean population is $6.5 \%$, as suggested by the American Diabetes Association (ADA). When 4,610 individuals with data from a 75-g OGTT and no previous history of DM were analyzed, individuals with impaired fasting glucose were classified into FPG 100 to $109 \mathrm{mg} / \mathrm{dL}$ and 110 to $125 \mathrm{mg} / \mathrm{dL}$ levels [5]. More individuals with FPG 110 to $125 \mathrm{mg} / \mathrm{dL}$ were diagnosed with DM as determined by a 2-hour plasma glucose result $\geq 200 \mathrm{mg} / \mathrm{dL}$ [5]. Therefore, to detect more cases of DM, the 75-g OGTT is recommended for all individuals with FPG 110 to $125 \mathrm{mg} / \mathrm{dL}$.

\section{TARGETS OF GLYCEMIC, BLOOD PRESSURE, AND LIPID CONTROL}

In the Kumamoto study [6] and the UK Prospective Diabetes Study (UKPDS) study [7], intensive glycemic control proved to be effective in preventing microvascular complications, and long-term follow-up of UKPDS cohorts [7] showed enduring effects of early glycemic control on microvascular complications. In the Kumamoto study [6], the goal of the intensive glucose control group was to maintain the blood glucose control as close as possible to FPG $<140 \mathrm{mg} / \mathrm{dL}$, 2-hour post-prandial blood glucose $<200 \mathrm{mg} / \mathrm{dL}$, and HbA1c $<7 \%$. The actual HbAlc level achieved was $7.1 \%$. During the 6-year study period, retinopathy decreased by $69 \%$, nephropathy decreased by $70 \%$, and nerve conduction velocity improved in the intensive glycemic control group [6]. The researchers suggested that the glycemic threshold to prevent the onset and progression of microvascular complications was indicated as follows: $\mathrm{HbAlc}<6.5 \%, \mathrm{FPG}<110 \mathrm{mg} / \mathrm{dL}$, and 2-hour post-prandial blood glucose $<180 \mathrm{mg} / \mathrm{dL}$ [6]. Many

Table 1. Diagnostic criteria for type 2 diabetes mellitus in Korea

1. Glycated hemoglobin (HbAlc) level $\geq 6.5 \%$ (HbAlc concentration must be measured through a standardized method) ${ }^{2}$

or

2. Eight-hour fasting plasma glucose of $\geq 126 \mathrm{mg} / \mathrm{dL}^{\mathrm{a}}$

or

3. Plasma glucose concentration of $\geq 200 \mathrm{mg} / \mathrm{dL}$ at 2 hours after a $75-\mathrm{g}$ oral glucose tolerance test ${ }^{\mathrm{a}}$

or

4. Classic symptoms of diabetes (polyuria, polydipsia, unexplained weight loss) with a random plasma glucose concentration of $\geq 200 \mathrm{mg} / \mathrm{dL}$

${ }^{2}$ Diagnosis must be confirmed through a repeat test on a different day. However, if more than two criteria are met on the same day, a definite diagnosis can be made. 
Table 2. Targets of glycemic, blood pressure, and lipid control in patients with type 2 diabetes mellitus

\begin{tabular}{lll}
\hline Cardiovascular diseases & Present & Absent \\
\hline HbA1c, $\%$ & $<6.5$ & \\
Blood pressure, $\mathrm{mm} \mathrm{Hg}$ & $<130 / 80$ & $<140 / 85$ \\
Lipid profiles & & \\
LDL-C, mg/dL & $<70$ & $<100^{\mathrm{a}}$ \\
Triglycerides, mg/dL & $<150$ & \\
HDL-C, mg/dL & $>40$ (men) & \\
& $>50$ (women) \\
\hline
\end{tabular}

HbA1c, glycated hemoglobin; LDL-C, low density lipoprotein cholesterol; HDL-C, high density lipoprotein cholesterol.

aTarget LDL-C is $<70 \mathrm{mg} / \mathrm{dL}$ in the presence of target organ damage or cardiovascular risk factors.

meta-analyses consistently provided evidence for the clinical benefits of achieving and maintaining intensive glycemic control to prevent diabetic complications. Therefore, optimal HbAlc target for patients with T2DM is recommended to be $<6.5 \%$ (Table 2), especially in the recently diagnosed, young patients with T2DM without severe complications or hypoglycemia, through lifestyle modification (LSM) and glucose-lowering agents, including insulin. However, the glycemic target should be individualized based on patient characteristics and preference. In patients with a history of severe hypoglycemia or advanced diabetic complications, short life expectancy, or advanced age, the glycemic target must be individualized with consideration of risks of complications such as hypoglycemia. The recommended glycemic target for type $1 \mathrm{DM}$ is an $\mathrm{HbAlc}$ concentration of $<7.0 \%$.

The ADA recommends that the intensity of statin should be determined by the risk of cardiovascular disease (CVD) or the presence of CVD without setting a low density lipoprotein cholesterol (LDL-C) target [8]. However, the LDL-C-lowering effect of statins in the Asian population can be more prominent than in Western populations [9]. Clinical trials did not include enough Asian populations, so it is unreasonable to apply the ADA guidelines in Korea. However, multiple clinical trials have demonstrated the beneficial effects of statin therapy on atherosclerotic cardiovascular disease (ASCVD) outcomes in subjects with and without CVD [10]. In a study of patients with acute coronary syndrome or previous CVD, the use of highdose statins to reduce LDL-C to less than $70 \mathrm{mg} / \mathrm{dL}$ significantly reduced the risk of subsequent CVD [11]. Meta-analyses of randomized controlled trials demonstrated the benefits of statins in people without established CVD but with cardiovascular (CV) risk factors. The goal of LDL-C concentration is graded according to the risk level, and diabetic patients with CVD are classified as very high risk and should target LDL-C $<70 \mathrm{mg} / \mathrm{dL}$. In diabetic patients with target organ damages (albuminuria or glomerular filtration rate [GFR] $<60 \mathrm{~mL} / \mathrm{min} /$ $1.73 \mathrm{~m}^{2}$ ) or CVD risk factors (hypertension, smoking, family history of premature ASCVD), LDL-C target of $<70 \mathrm{mg} / \mathrm{dL}$ should be considered. In diabetic patients without CVD, the recommended target for LDL-C is $<100 \mathrm{mg} / \mathrm{dL}$.

In the Action to Control Cardiovascular Risk in Diabetes Blood Pressure (ACCORD-BP) study [12], an intensive blood pressure (BP) control strategy to achieve a systolic BP (SBP) $<120 \mathrm{~mm} \mathrm{Hg}$ did not significantly reduce the composite of CVD death, nonfatal myocardial infarction, and nonfatal stroke compared with a standard SBP control goal of $<140 \mathrm{~mm} \mathrm{Hg}$. In contrast, the Systolic Blood Pressure Intervention Trial (SPRINT) found a significant reduction in the number of CVD events with intensive BP control to a goal SBP of $<120 \mathrm{~mm} \mathrm{Hg}$ but excluded those patients with T2DM [13]. It was reported that intensive BP control to a goal SBP of $<120 \mathrm{~mm} \mathrm{Hg}$ significantly reduced the risk of CVD outcomes in SPRINT-eligible ACCORD-BP participants [14]. Participants with DM in that study were eligible for the analysis if they were in the standard glucose control arm of ACCORD-BP and had the additional CVD risk factors required for SPRINT. According to the 2017 American College of Cardiology/American Heart Association (ACC/AHA) guideline for the management of high BP in adults, in adults with DM and hypertension, antihypertensive drug treatment should be initiated at a BP of $130 / 80 \mathrm{~mm} \mathrm{Hg}$ or higher with a treatment goal of less than 130/80 $\mathrm{mm} \mathrm{Hg}$ [15].

The risk and incidence of CVD in the Asian population are different from those in Western populations [16]. For Asian populations, the risk of stroke compared with coronary artery disease is higher. In addition, the relationship between BP levels and stoke incidence is stronger in Asian populations, and the slope of association between BP levels and stroke events has also been shown to be steeper in Asians than in Western populations. The recent study of Korean cohort data among patients with T2DM without underlying CVD at baseline showed that a $\mathrm{BP}<130 / 80 \mathrm{~mm} \mathrm{Hg}$ was associated with further lowering of the risk of CV events [16], but an SBP $<110 \mathrm{~mm} \mathrm{Hg}$ or diastolic BP (DBP) $<75 \mathrm{~mm} \mathrm{Hg}$ was associated with a higher risk of all-cause mortality. However, there is no definitive study comparing the effect of lowering SBP to below $130 \mathrm{~mm} \mathrm{Hg}$ as op- 
posed to less than $140 \mathrm{~mm} \mathrm{Hg}$ in diabetic patients without CVD, and most of the studies mentioned earlier have been conducted in diabetic patients with CVD or with many CV risk factors. Therefore, there is no clear evidence to maintain SBP below $130 \mathrm{~mm} \mathrm{Hg}$ in diabetic patients without CVD. In a sub-analysis of the Hypertension Optimal Treatment (HOT) study, DBP control goals were divided into three groups, of 90 , 85, and $80 \mathrm{~mm} \mathrm{Hg}$ [17]. Unlike hypertensive patients without $\mathrm{DM}$, hypertensive patients with DM recognized CV benefits when lower DBP was achieved, and the actual DBP was $81 \mathrm{~mm}$ $\mathrm{Hg}$ in the group aiming at less than $80 \mathrm{~mm} \mathrm{Hg}$. The target BP for diabetic patients is recommended $<140 / 85 \mathrm{~mm} \mathrm{Hg}$. However, the target BP for diabetic patients with CVD should be considered $<130 / 80 \mathrm{~mm} \mathrm{Hg}$.

\section{OBESITY MANAGEMENT FOR THE TREATMENT OF TYPE 2 DIABETES MELLITUS}

According to the 2018 Korean Society for the Study of Obesity guidelines [18], the classification of obesity into classes I, II, and III relies on adult BMI, in accordance with WHO guidelines for the Asia-Pacific region. Class I obesity is defined as BMI $25 \mathrm{~kg} / \mathrm{m}^{2}$ to less than $30 \mathrm{~kg} / \mathrm{m}^{2}$, class II obesity is defined as BMI $30 \mathrm{~kg} / \mathrm{m}^{2}$ to less than $35 \mathrm{~kg} / \mathrm{m}^{2}$, and class III obesity was newly defined in 2018 as greater than $35 \mathrm{~kg} / \mathrm{m}^{2}$. If a patient with T2DM and BMI $>25 \mathrm{~kg} / \mathrm{m}^{2}$ (class I) fails to lose weight with diet, physical activity, and behavior counseling, weightloss medications may be considered.

Bariatric surgery should be considered in patients with $\mathrm{T} 2 \mathrm{DM}$ if $\mathrm{BMI} \geq 35 \mathrm{~kg} / \mathrm{m}^{2}$ (class III obesity). Bariatric surgery may be considered in patients with $\mathrm{T} 2 \mathrm{DM} \geq \mathrm{BMI} 30 \mathrm{~kg} / \mathrm{m}^{2}$ (class II obesity) if nonsurgical treatment fails to result in weight loss or glycemic control. A substantial body of evidence has now been accumulated, including data from randomized controlled clinical trials, demonstrating that bariatric surgery achieves superior glycemic control and reduction of CV risk factors in patients with T2DM and obesity compared with various medical interventions [19]. However, it is also reported that $35 \%$ to $50 \%$ of patients who initially achieve remission of DM after bariatric surgery eventually experience recurrence [20]. Regardless of remission of DM, nearly all patients with T2DM and obesity who undergo bariatric surgery maintain significant improvements of glycemic control and other CV risk factors. Thus, it is important to recognize bariatric surgery as one treatment for the management of obesity and DM rather than focusing on the remission of DM after bariatric surgery.

\section{ANTIHYPERGLYCEMIC THERAPY FOR ADULT PATIENTS WITH TYPE 2 DIABETES MELLITUS}

LSM is an essential component of treatment for all patients with T2DM and should be initiated promptly and simultaneously with antihyperglycemic agents. Patients' education within a structured program should be provided from a health care professional at the time of diagnosis and then followed up with regular reinforcement checks. For patients with newly diagnosed T2DM, LSM that includes medical nutrition therapy, weight control, physical activity, smoking cessation, and avoidance of alcohol abuse should be initiated.

As an initial therapy for newly diagnosed patients with an $\mathrm{HbAlc}<7.5 \%$, metformin must first be considered as first-line oral therapy but other drugs can be considered based on patient status [21]. If metformin is not tolerable or is contraindicated, the alternative choices for monotherapy include dipeptidyl peptidase-4 (DPP-4) inhibitors, sodium-glucose cotransporter-2 (SGLT2) inhibitors, thiazolidinediones (TZDs), glucagon-like peptide 1 receptor agonists (GLP-1 RAs), sulfonylureas (SUs), glinides, $\alpha$-glucosidase inhibitors, and insulin according to patient circumstances. In the Practical Evidence of Antidiabetic Monotherapy (PEAM) study, the glucose-lowering efficacies of SUs, metformin, and TZDs as antidiabetic monotherapies administered for 48 weeks were similar in drug-naïve Korean patients diagnosed with T2DM [22].

If the initial $\mathrm{HbAlc}$ level of a patient is $\geq 7.5 \%$ or the $\mathrm{HbAlc}$ target is not achieved within three months of initiating monotherapy, dual combination therapy can be considered. If the HbAlc target is not achieved within 3 months of initiating dual therapy, a third agent with a complementary mechanism of action can be added for triple combination therapy. The early combination therapy is preferred over maximizing the dosage of a single agent when considering glucose-lowering efficacy and side effects. Although there is no particular order of preference, efficacy, risk of hypoglycemia, weight gain, CV benefits, and presence of clinical data in the Korean population should be considered for this arrangement (Fig. 1) [23]. Metformin is maintained as background therapy during dual or triple combination therapy.

In the Empagliflozin Cardiovascular Outcome Event Trial in 


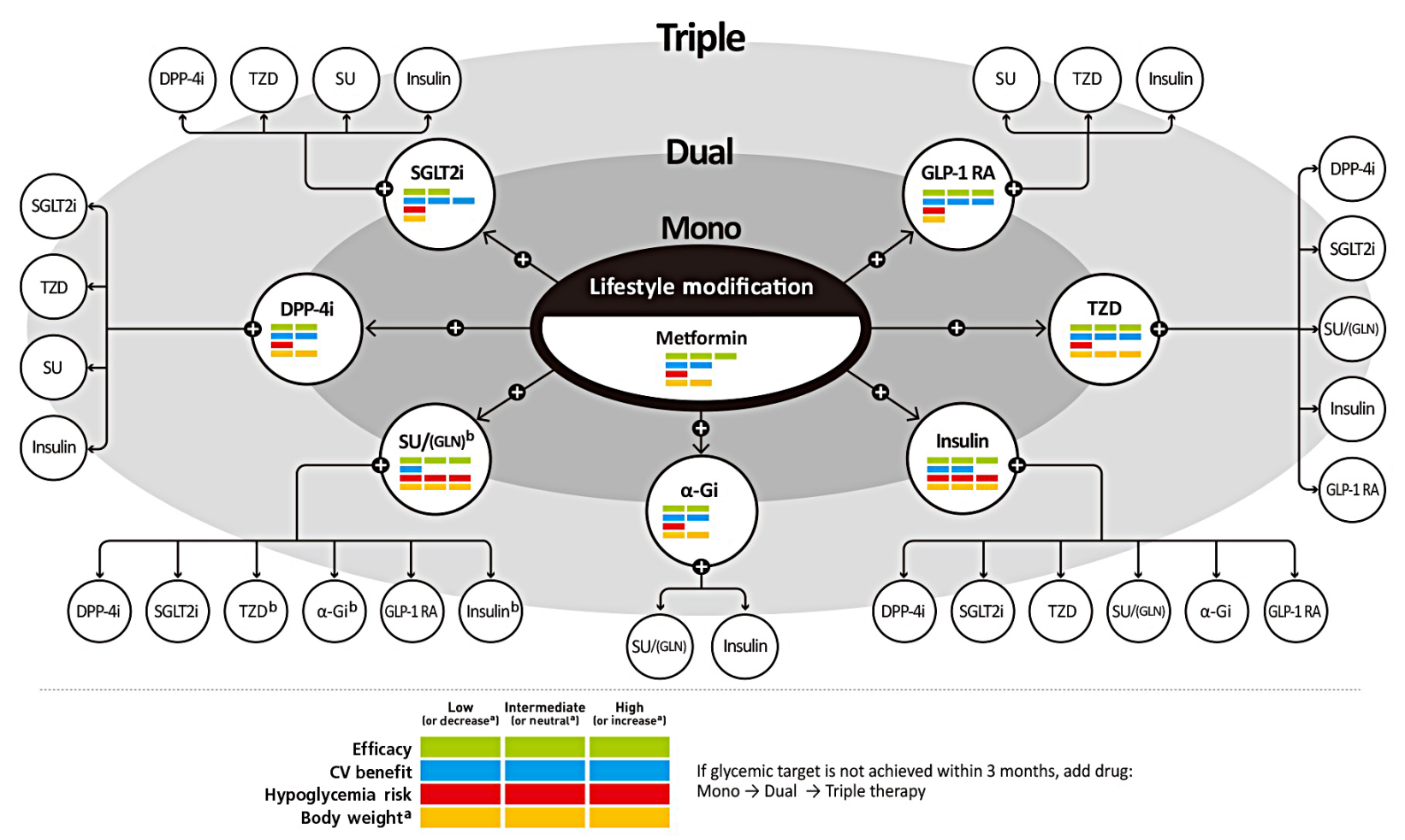

Fig. 1. Antihyperglycemic therapy algorithm for adult patients with type 2 diabetes mellitus (T2DM). The algorithm stratifies the choice of medications for T2DM based on initial glycated hemoglobin (HbAlc) levels and demonstrates drug arrangement in a centrifugal direction. This algorithm includes only U.S. Food and Drug Administration-approved classes of medications for T2DM that are prescribed in Korea. For newly diagnosed T2DM, begin with lifestyle modification (LSM) at the time of diagnosis and maintain these changes subsequently for the duration of treatment. The HbAlc target is $<6.5 \%$; if this is not achieved within 3 months after implementing LSM, then the use of an antihyperglycemic agent should be initiated promptly. If the HbAlc level is $<7.5 \%$, metformin monotherapy is the preferred choice for pharmacotherapy in conjunction with LSM. If there are contraindications for metformin or side effects, then consider other monotherapy options such as a dipeptidyl peptidase-4 inhibitor (DPP-4i), sodium-glucose cotransporter-2 inhibitor (SGLT2i), thiazolidinedione (TZD), glucagon-like peptide 1 receptor agonists (GLP-1 $\mathrm{RAs}$ ), sulfonylurea (SU), $\alpha$-glucosidase inhibitor ( $\alpha-\mathrm{Gi})$, or insulin as the initial therapy according to the patient's condition. If the initial $\mathrm{HbAlc}$ level is $\geq 7.5 \%$ or the HbAlc target is not achieved within 3 months of monotherapy, dual combination therapy can be considered. In this case, a second-line drug is added to metformin; however, any other combination of drugs with different mechanisms of action can be used depending on the patient's clinical characteristics. If the HbAlc target is not achieved within 3 months after commencing dual therapy, then proceed to triple combination therapy. In no particular order of preference, efficacy, cardiovascular benefit, risk of hypoglycemia, impact of body weight, and presence of clinical data in the Korean population should be considered for this arrangement. To aid the physician's choice, the characteristics of antihyperglycemic agent classes are shown as a bar scale. Efficacy (green), CV benefit (blue), hypoglycemia risk (red), and body weight changes (yellow) were assigned ratings of low, intermediate, or high (body weight changes; decrease, neutral, or increase) based on recently published studies identified in an extensive literature review; the scale bar is not constructed according to strict definitions but should be used as a guide for clinical decisions. This figure was illustrated based on the drugs' approval by the Korea Food and Drug Administration (http://www.mfds. go.kr/eng) in April 2019 [23]. GLN, glinide. ${ }^{a}$ Body weight changes: decrease, neutral, or increase, ${ }^{b}$ GLN can be used as dual combination therapy with metformin, TZD, $\alpha-\mathrm{Gi}$, or insulin or as a triple combination therapy with metformin and $\alpha-\mathrm{Gi}$, metformin and TZD, or metformin and insulin.

Type 2 Diabetes Mellitus Patients-Removing Excess Glucose (EMPA-REG OUTCOME) trial, empagliflozin added to the standard of care reduced the risk of three-point major adverse cardiovascular events (three-point MACE: composite of CV death, nonfatal myocardial infarction, or nonfatal stroke) by $14 \%$, CV death by $38 \%$, hospitalization for heart failure by $35 \%$, and all-cause mortality by $32 \%$ in patients with T2DM and established CVD [24]. When the effects of empagliflozin 


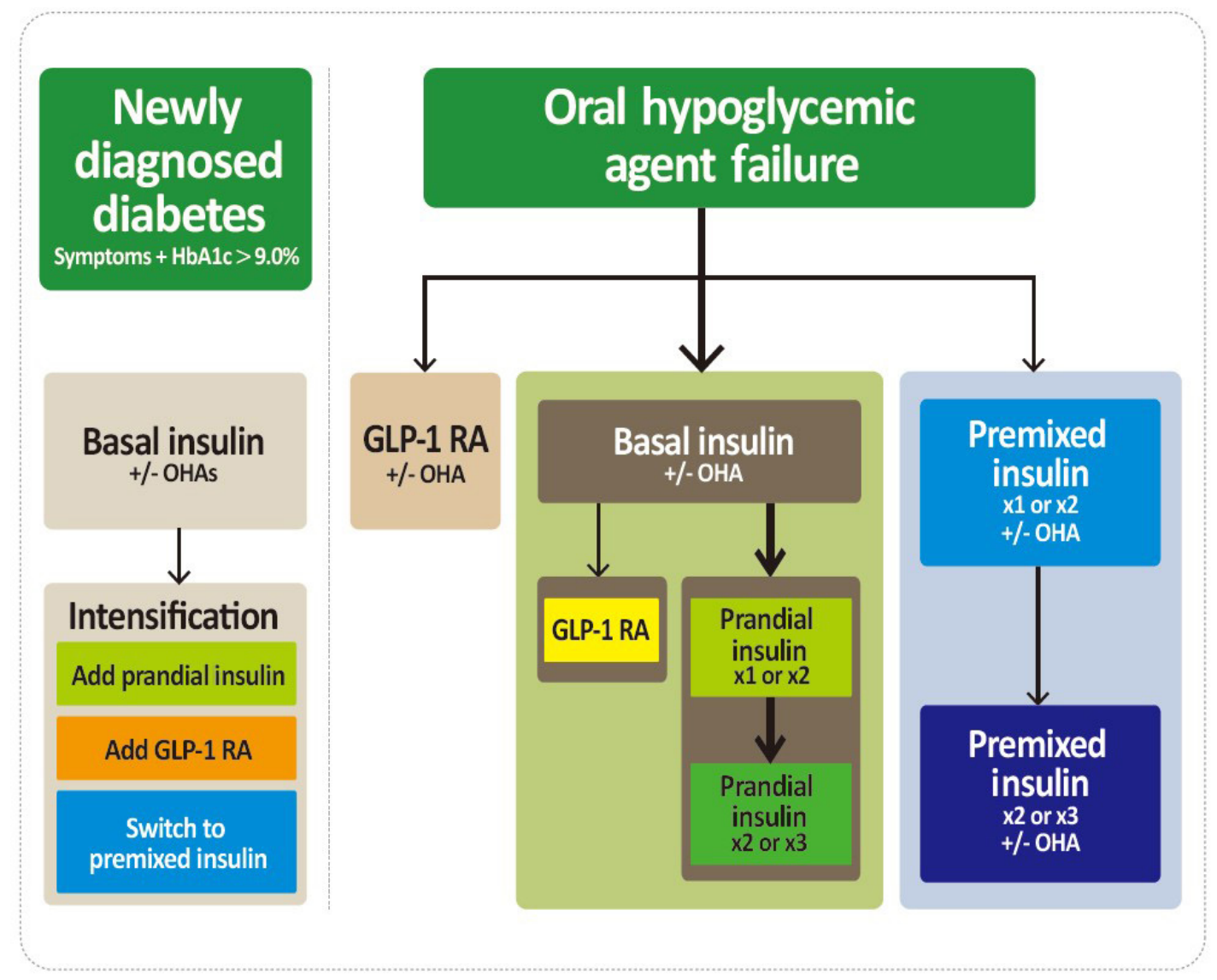

Fig. 2. Treatment algorithm for injectable therapy in type 2 diabetes mellitus (T2DM). (Left) Initiation of insulin treatment. If the initial glycated hemoglobin (HA1c) level is $>9.0 \%$ and symptomatic hyperglycemia or metabolic decompensation is present, insulin therapy can be initiated with or without oral antihyperglycemic agents (OHAs) in patients with newly diagnosed T2DM. If the HAlc target range is not achieved after implementing a basal insulin regimen, then proceed to intensification treatment, for example, addition of a glucagon-like peptide 1 receptor agonist (GLP-1 RA) or a prandial insulin or switching to a premixed insulin regimen. (Right) For adult patients with T2DM who have not achieved their glycemic target following adequate treatment using OHAs. When OHAs fail, proceed to basal insulin either with or without OHAs. The addition of a GLP-1 RA or switching to a premixed insulin regimen could be another option depending on the patient's clinical situation. The width of each black line reflects the strength of the expert consensus recommendations. In patients above the HbAlc target on basal insulin or premixed insulin once or twice daily, further intensification outlined in this algorithm may be considered.

in Asian patients were investigated $(n=1,517)$, empagliflozin reduced the risk of three-point MACE by $32 \%$ (hazard ratio, 0.68 ; $95 \%$ confidence interval, 0.48 to 0.95 ) [25]. The effects of empagliflozin on the components of MACE, all-cause mortality, and heart failure outcomes in Asian patients were consistent with the overall population [25]. Therefore, for patients with established ASCVD, the SGLT2 inhibitors with proven CV benefits should first be considered.

The GLP-1 RAs with proven CV benefits should be considered [26,27]. The GLP-1 RAs can be used in monotherapy or in combination with oral hypoglycemic agents other than
DPP-4 inhibitors or in combination with basal insulin. Especially, the GLP-1 RAs with proven CV benefits should be considered in T2DM patients with established CVD [26,27]. Both liraglutide and semaglutide significantly reduced a composite three-point MACE outcome and mortality compared with placebo-treated group [26,27]. For patients with T2DM who fail to achieve the glycemic target with adequate treatment with oral antihyperglycemic agents, proceed to insulin injection therapy. The addition of a GLP-1 RA or switching to a premixed insulin regimen could be another option depending on the patient's clinical situation (Fig. 2). The initiation of insu- 
lin should be considered in patients with newly-diagnosed T2DM if the initial HbA1c level is $>9.0 \%$ and symptomatic hyperglycemia or metabolic decompensation is present. Insulin also should be considered when adequate glycemic control is not obtained in patients with decompensated hepatic or renal insufficiency and when patients have suffered from myocardial infarction, stoke, or a major operation [28].

\section{DIABETIC NEPHROPATHY}

It is recommended that urinary albumin excretion and estimated GFR should be assessed at least once a year. A urine albumin-creatinine ratio $\geq 30 \mathrm{mg} / \mathrm{g}$ is generally defined as albuminuria, and decreased GFR is defined as GFR $<60 \mathrm{~mL} / \mathrm{min} /$ $1.73 \mathrm{~m}^{2}$. Angiotensin-converting enzyme inhibitors and angiotensin II receptor antagonists are recommended as first-line medications for BP control in diabetic patients with albuminuria. Glycemic control has been shown to be effective to slow the progression of nephropathy in patients with early diabetic nephropathy. Recently, several hypoglycemic agents demonstrated beneficial effects on the progression of diabetic nephropathy. Empagliflozin showed a significantly lower risk of albuminuria progression or renal outcomes, such as a doubling of the serum creatinine level and initiation of renal-replacement therapy, than the placebo group [29]. Some GLP-1 RAs also demonstrated a renal protective effect in the Liraglutide Effect and Action in Diabetes: Evaluation of Cardiovascular Outcome Results (LEADER) and the Preapproval Trial to Evaluate Cardiovascular and Other Long-term Outcomes with Semaglutide in Subjects with Type 2 Diabetes (SUSTAIN-6) trials $[26,30]$. However, their renal outcome was studied as a secondary outcome. Recently, in T2DM with renal disease, canagloflozin lowered the risk of kidney failure or renal death about $30 \%$ than in the placebo group [31].

Appropriate clinical practice guidelines customized for Korean people with T2DM have been developed and updated to provide better glycemic control and favorable clinical outcomes. More evidence and clinical trials should be undertaken, especially in Asia, including Korea.

\section{CONFLICTS OF INTEREST}

No potential conflict of interest relevant to this article was reported.

\section{ORCID}

Mee Kyoung Kim https://orcid.org/0000-0003-3205-9114

Hyuk-Sang Kwon https://orcid.org/0000-0003-4026-4572

\section{ACKNOWLEDGMENTS}

None

\section{REFERENCES}

1. Won JC, Lee JH, Kim JH, Kang ES, Won KC, Kim DJ, Lee MK. Diabetes fact sheet in Korea, 2016: an appraisal of current status. Diabetes Metab J 2018;42:415-24.

2. American Diabetes Association. 10. Cardiovascular disease and risk management: standards of medical care in diabetes-2019. Diabetes Care 2019;42:S103-23.

3. Ko SH, Kim SR, Kim DJ, Oh SJ, Lee HJ, Shim KH, Woo MH, Kim JY, Kim NH, Kim JT, Kim CH, Kim HJ, Jeong IK, Hong EK, Cho JH, Mok JO, Yoon KH; Committee of Clinical Practice Guidelines, Korean Diabetes Association. 2011 Clinical practice guidelines for type 2 diabetes in Korea. Diabetes Metab J 2011;35:431-6.

4. Hong S, Kang JG, Kim CS, Lee SJ, Lee CB, Ihm SH. Fasting plasma glucose concentrations for specified HbAlc goals in Korean populations: data from the Fifth Korea National Health and Nutrition Examination Survey (KNHANES V-2, 2011). Diabetol Metab Syndr 2016;8:62.

5. Oh JY, Lim S, Kim DJ, Kim NH, Kim DJ, Moon SD, Jang HC, Cho YM, Song KH, Ahn CW, Sung YA, Park JY, Shin C, Lee HK, Park KS; Committee of the Korean Diabetes Association on the Diagnosis and Classification of Diabetes Mellitus. A report on the diagnosis of intermediate hyperglycemia in Korea: a pooled analysis of four community-based cohort studies. Diabetes Res Clin Pract 2008;80:463-8.

6. Ohkubo Y, Kishikawa H, Araki E, Miyata T, Isami S, Motoyoshi S, Kojima Y, Furuyoshi N, Shichiri M. Intensive insulin therapy prevents the progression of diabetic microvascular complications in Japanese patients with non-insulin-dependent diabetes mellitus: a randomized prospective 6-year study. Diabetes Res Clin Pract 1995;28:103-17.

7. Holman RR, Paul SK, Bethel MA, Matthews DR, Neil HA. 10Year follow-up of intensive glucose control in type 2 diabetes. N Engl J Med 2008;359:1577-89.

8. American Diabetes Association. 2. Classification and diagnosis 
of diabetes: standards of medical care in diabetes-2019. Diabetes Care 2019;42:S13-28.

9. Naito R, Miyauchi K, Daida H. Racial differences in the cholesterol-lowering effect of statin. J Atheroscler Thromb 2017;24: 19-25.

10. Brugts JJ, Yetgin T, Hoeks SE, Gotto AM, Shepherd J, Westendorp RG, de Craen AJ, Knopp RH, Nakamura H, Ridker P, van Domburg R, Deckers JW. The benefits of statins in people without established cardiovascular disease but with cardiovascular risk factors: meta-analysis of randomised controlled trials. BMJ 2009;338:b2376.

11. Ahmed S, Cannon CP, Murphy SA, Braunwald E. Acute coronary syndromes and diabetes: is intensive lipid lowering beneficial? Results of the PROVE IT-TIMI 22 trial. Eur Heart J 2006;27:2323-9.

12. ACCORD Study Group, Cushman WC, Evans GW, Byington RP, Goff DC Jr, Grimm RH Jr, Cutler JA, Simons-Morton DG, Basile JN, Corson MA, Probstfield JL, Katz L, Peterson KA, Friedewald WT, Buse JB, Bigger JT, Gerstein HC, Ismail-Beigi F. Effects of intensive blood-pressure control in type 2 diabetes mellitus. N Engl J Med 2010;362:1575-85.

13. SPRINT Research Group, Wright JT Jr, Williamson JD, Whelton PK, Snyder JK, Sink KM, Rocco MV, Reboussin DM, Rahman M, Oparil S, Lewis CE, Kimmel PL, Johnson KC, Goff DC Jr, Fine LJ, Cutler JA, Cushman WC, Cheung AK, Ambrosius WT. A randomized trial of intensive versus standard bloodpressure control. N Engl J Med 2015;373:2103-16.

14. Buckley LF, Dixon DL, Wohlford GF 4th, Wijesinghe DS, Baker WL, Van Tassell BW. Intensive versus standard blood pressure control in SPRINT-eligible participants of ACCORD-BP. Diabetes Care 2017;40:1733-8.

15. Whelton PK, Carey RM, Aronow WS, Casey DE Jr, Collins KJ, Dennison Himmelfarb C, DePalma SM, Gidding S, Jamerson KA, Jones DW, MacLaughlin EJ, Muntner P, Ovbiagele B, Smith SC Jr, Spencer CC, Stafford RS, Taler SJ, Thomas RJ, Williams KA Sr, Williamson JD, Wright JT Jr. 2017 ACC/AHA/AAPA/ ABC/ACPM/AGS/APhA/ASH/ASPC/NMA/PCNA guideline for the prevention, detection, evaluation, and management of high blood pressure in adults: a report of the American College of Cardiology/American Heart Association Task Force on Clinical Practice Guidelines. Hypertension 2018;71:e13-115.

16. Kim MK, Han K, Koh ES, Kim ES, Lee MK, Nam GE, Kwon HS. Blood pressure and development of cardiovascular disease in Koreans with type 2 diabetes mellitus. Hypertension 2019; 73:319-26.
17. Hansson L, Zanchetti A, Carruthers SG, Dahlof B, Elmfeldt D, Julius S, Menard J, Rahn KH, Wedel H, Westerling S. Effects of intensive blood-pressure lowering and low-dose aspirin in patients with hypertension: principal results of the Hypertension Optimal Treatment (HOT) randomised trial. HOT Study Group. Lancet 1998;351:1755-62.

18. Seo MH, Lee WY, Kim SS, Kang JH, Kang JH, Kim KK, Kim BY, Kim YH, Kim WJ, Kim EM, Kim HS, Shin YA, Shin HJ, Lee KR, Lee KY, Lee SY, Lee SK, Lee JH, Lee CB, Chung S, Cho YH, Choi KM, Han JS, Yoo S); Committee of Clinical Practice Guidelines, Korean Society for the Study of Obesity (KSSO). 2018 Korean Society for the Study of Obesity guideline for the management of obesity in Korea. J Obes Metab Syndr 2019;28: 40-5.

19. Schauer PR, Bhatt DL, Kirwan JP, Wolski K, Aminian A, Brethauer SA, Navaneethan SD, Singh RP, Pothier CE, Nissen SE, Kashyap SR; STAMPEDE Investigators. Bariatric surgery versus intensive medical therapy for diabetes: 5-year outcomes. N Engl J Med 2017;376:641-51.

20. Sjostrom L, Peltonen M, Jacobson P, Ahlin S, Andersson-Assarsson J, Anveden A, Bouchard C, Carlsson B, Karason K, Lonroth H, Naslund I, Sjostrom E, Taube M, Wedel H, Svensson PA, Sjoholm K, Carlsson LM. Association of bariatric surgery with long-term remission of type 2 diabetes and with microvascular and macrovascular complications. JAMA 2014; 311:2297-304.

21. Ko SH, Hur KY, Rhee SY, Kim NH, Moon MK, Park SO, Lee BW, Kim HJ, Choi KM, Kim JH; Committee of Clinical Practice Guideline of Korean Diabetes Association. Antihyperglycemic agent therapy for adult patients with type 2 diabetes mellitus 2017: a position statement of the Korean Diabetes Association. Diabetes Metab J 2017;41:337-48.

22. Yoon KH, Shin JA, Kwon HS, Lee SH, Min KW, Ahn YB, Yoo SJ, Ahn KJ, Park SW, Lee KW, Sung YA, Park TS, Kim MS, Kim YK, Nam MS, Kim HS, Park IeB, Park JS, Woo JT, Son HY. Comparison of the efficacy of glimepiride, metformin, and rosiglitazone monotherapy in Korean drug-naïve type 2 diabetic patients: the Practical Evidence of Antidiabetic Monotherapy study. Diabetes Metab J 2011;35:26-33.

23. Ministry of Food and Drug Safety: Drug information. Available from: https://nedrug.mfds.go.kr (cited 2019 Jul 16).

24. Zinman B, Wanner C, Lachin JM, Fitchett D, Bluhmki E, Hantel S, Mattheus M, Devins T, Johansen OE, Woerle HJ, Broedl UC, Inzucchi SE; EMPA-REG OUTCOME Investigators. Empagliflozin, cardiovascular outcomes, and mortality in type 2 
diabetes. N Engl J Med 2015;373:2117-28.

25. Kaku K, Lee J, Mattheus M, Kaspers S, George J, Woerle HJ; EMPA-REG OUTCOME(R) Investigators. Empagliflozin and cardiovascular outcomes in Asian patients with type 2 diabetes and established cardiovascular disease: results from EMPAREG OUTCOME(R). Circ J 2017;81:227-34.

26. Marso SP, Bain SC, Consoli A, Eliaschewitz FG, Jodar E, Leiter LA, Lingvay I, Rosenstock J, Seufert J, Warren ML, Woo V, Hansen O, Holst AG, Pettersson J, Vilsboll T; SUSTAIN-6 Investigators. Semaglutide and cardiovascular outcomes in patients with type 2 diabetes. N Engl J Med 2016;375:1834-44.

27. Marso SP, Daniels GH, Brown-Frandsen K, Kristensen P, Mann JF, Nauck MA, Nissen SE, Pocock S, Poulter NR, Ravn LS, Steinberg WM, Stockner M, Zinman B, Bergenstal RM, Buse JB; LEADER Steering Committee; LEADER Trial Investigators. Liraglutide and cardiovascular outcomes in type 2 diabetes. N Engl J Med 2016;375:311-22.

28. Malmberg K, Norhammar A, Wedel H, Ryden L. Glycometabolic state at admission: important risk marker of mortality in conventionally treated patients with diabetes mellitus and acute myocardial infarction: long-term results from the Diabetes and Insulin-Glucose Infusion in Acute Myocardial Infarction (DIGAMI) study. Circulation 1999;99:2626-32.

29. Wanner C, Inzucchi SE, Lachin JM, Fitchett D, von Eynatten M, Mattheus M, Johansen OE, Woerle HJ, Broedl UC, Zinman B; EMPA-REG OUTCOME Investigators. Empagliflozin and progression of kidney disease in type 2 diabetes. $\mathrm{N}$ Engl J Med 2016;375:323-34.

30. Mann JFE, Orsted DD, Brown-Frandsen K, Marso SP, Poulter NR, Rasmussen S, Tornoe K, Zinman B, Buse JB; LEADER Steering Committee and Investigators. Liraglutide and renal outcomes in type 2 diabetes. N Engl J Med 2017;377:839-48.

31. Perkovic V, Jardine MJ, Neal B, Bompoint S, Heerspink HJL, Charytan DM, Edwards R, Agarwal R, Bakris G, Bull S, Cannon CP, Capuano G, Chu PL, de Zeeuw D, Greene T, Levin A, Pollock C, Wheeler DC, Yavin Y, Zhang H, Zinman B, Meininger G, Brenner BM, Mahaffey KW; CREDENCE Trial Investigators. Canagliflozin and renal outcomes in type 2 diabetes and nephropathy. N Engl J Med 2019;380:2295-306. 